\title{
Nurse Managers' Strategies for the Integration of Newly Graduated Nurses into Clinical Units in Japan: A Qualitative Exploratory Study
}

\author{
Misuzu F. Gregg ${ }^{*}, 1$, Toyomi Wakisaka ${ }^{2}$ and Chifuyu Hayashi ${ }^{1}$ \\ ${ }^{1}$ Kobe City College of Nursing, Kobe, Japan \\ ${ }^{2}$ Konan Women's University, Kobe, Japan
}

\begin{abstract}
Aim: The purpose of this study was to explore the strategies used by nurse managers in Japan to facilitate the integration of newly graduate nurses (NGNs) into their clinical units.

Background: The integration of NGNs into clinical units is an important issue for both NGNs and nurse managers because the first year of practice plays a vital role in a NGN's career.

Method: Data were generated through semi-structured interviews with 9 nurse managers in 9 acute care hospitals. Data analysis was conducted using a qualitative content analysis method.

Results: Nurse managers used a total of 6 strategies: understanding the circumstances of NGNs, providing opportunities for experience and learning, supporting nurses who teach NGNs, facilitating self-learning, promoting awareness of being a nurse in the clinical unit, and strengthening the sense of comradeship in clinical units. Three of these strategies were particularly important for NGNs' integration into clinical units: facilitating self-learning, promoting awareness of being a nurse in the clinical unit, and strengthening the sense of comradeship in clinical units. These strategies were described in this study.

Conclusions: The strategies adopted by nurse managers should be aimed at all nurses, not just NGNs, in order to strengthen the sense of comradeship in clinical units. This approach would create a supportive environment for the integration of NGNs into clinical units. The strategies presented in this study can be utilized not just by nurse managers but all senior nurses in the unit. NGNs can use these strategies to help them understand what they need to do to become a full member of their unit.
\end{abstract}

Keywords: Clinical units, integration, newly graduated nurses, nurse managers, qualitative descriptive study, strategies.

\section{INTRODUCTION}

Even though it has been 40 years since Kremer [1] wrote her book about reality shock, making a smooth transition from student to nurse remains an important issue attended by certain difficulties. The difficulties are partially caused by the NGN's lack of clinical experience and skills when working in acute care hospitals that require a high level of acuity and in which patient care is often complex [2]. The gap between NGNs' clinical competency and knowledge and the skills needed for clinical practice is an issue not confined to Japan [3, 4]. For the transition to be accomplished successfully, it is important for NGNs to integrate into their clinical units. According to the American Organization of Nurse Executives (AONE) guiding principles to aid the NGNs' integration into a practice setting, the nurse manager is the key person for ensuring that NGNs succeed in their endeavors [5]. However, little study on how nurse managers help NGNs to integrate into their clinical units has been conducted.

*Address correspondence to this author at the 3-4 GakuenNishi-machi, Nishi-ku, Kobe-shi, Hyogo-ken, 651-2103, Japan; Tel/Fax: 81-78-794-8045; E-mail: m-gregg@tr.kobe-ccn.ac.jp
Therefore, this study aimed to identify what kinds of strategies nurse managers use to facilitate the integration of NGNs into clinical units. Adapting the definition of organizational socialization formulated by Van Maanen and Schein [6] in this study, "integration into their clinical unit" is defined as the process by which a NGN acquires the attitudes, behavior, and knowledge needed to be a member of the unit.

\section{BACKGROUND}

The Japanese Nursing Association conducted surveys to ascertain why NGNs leave their job within their first year [7]. The deans or chiefs of nursing schools responded to the survey. The top three factors that made it difficult for NGNs to continue working were a gap between the competencies acquired while at nursing school and the competencies actually needed in the workplace, lack of maturity and resilience among the present generation of young people, and the requirement that a higher standard of competency than before be met. The nursing directors at hospitals also responded to the same question. The top three factors that made continuation difficult were identical. In the same survey, NGNs responded to a question about what caused them distress as a nurse. About $80 \%$ answered that they did not have sufficient knowledge and skills to work at their 
clinical unit. The second source of distress was the anxiety associated with making medical errors. These experiences of Japanese NGNs are reflected in other countries $[3,8,9]$.

Successfully making the transition from student to registered nurse is an important issue for NGNs because NGNs' integration into a clinical unit happens as a result of this transition. Some strategies were reported as being useful in assisting NGNs to make this role transition. As a hospital level approach, the national post-baccalaureate nursing residency program in the U.S. and the graduate nursing program in Australia are well known. As a clinical unit level approach, using a questionnaire survey, Scott et al. [10] identified that orientation programs play a critical role in job satisfaction and retention of NGNs. Creating a specially designed orientation program that takes into account the expectations of both the hospital and NGNs was reported to be an effective way of facilitating the transition from student to nurse [11]. Furthermore, the effectiveness of preceptorship to bridge the gap between being a student to fulfilling the role of a nurse has been documented [12]. The mentoring program in an operating room reduced the turnover rate of newly hired nurses by helping their integration into the practice environment [13]. Taking these strategies together, nurse managers play an important part in helping NGNs to integrate into clinical units. The integration of NGNs into a clinical unit has impact on not only NGNs' job satisfaction but also on all nurses in the unit and eventually it influences the quality of care provided in the unit.

\section{METHODOLOGY}

\section{Design}

The purpose of this study was to explore the strategies used by nurse managers to facilitate the integration of NGNs into clinical units in everyday practice. A qualitative descriptive research approach was chosen because it is suitable for describing everyday events in everyday terms [14].

\section{Study Participants}

A convenience sampling technique was adopted for this study. The study participants were 9 nurse managers who worked at 9 clinical units in 9 acute care hospitals. Nurse managers were the target of this study because clinical units in Japan do not have their own nurse educator; therefore, nurse managers are in charge of NGNs' education. The hospitals were selected by the authors based on relationships with the hospitals such as the clinical practice fields of the students. Originally, it was planned to hold interviews with10 nurse managers; however, one nurse manager declined to be interviewed and introduced a nurse who was in charge of NGN education. This interview was excluded from the data of this study.

The criterion used to select clinical units was "places where nurses were working cohesively as a unit". This criterion was established because it was reasonable to assume that the nurse managers of these clinical units had strategies that would facilitate the integration of NGNs into their clinical units. The directors of nursing of 9 hospitals selected the clinical units which met the selection criterion and introduced the authors to the nurse managers.

\section{Data Generation}

The authors who gathered the data are nurse researchers who as a group have been studying NGN education for 7 years. Data were generated through semi-structured interviews. Nine interviews were conducted by 3 authors and each interview lasted 60 to 75 minutes. The authors discussed each interview and confirmed that the same direction was followed based on the purpose of the study. This approach, in which all authors conducted their own interviews, helped with data analysis and facilitated discussion during the analysis. All interviews were digitally recorded and transcribed verbatim.

The interview guide was designed based on a literature review related to the transition and socialization of NGNs. The interview guide included questions regarding important approaches taken in the teaching of NGNs in a clinical unit, the atmosphere of the unit in which NGNs worked, and strategies to facilitate NGNs' integration into a clinical unit.

\section{Data Analysis}

Data analysis was conducted using a qualitative content analysis method [14-16]. Transcriptions of digitally recorded interviews were read carefully and the content was analyzed by scrutinizing each sentence and then the sentences were coded. The first author examined all codes and compared them for any similarities and differences and sorted the codes to identify clusters of codes, and extracted subcategories. These subcategories were compared with each other for any similarities in order to extract categories. The other 2 authors examined this process and confirmed that all the extracted categories fitted the interview data. During this process, the authors held discussions until a consensus was reached.

The rigor of this study was assessed based on credibility, transferability, dependability, and confirmability [17]. The rigor of the data analysis was confirmed by member checking with 2 study participants. The interviews were conducted by the first author. These study participants confirmed the data analysis was a good description of the strategies used by nurse managers to facilitate NGNs' integration into clinical units. This process conferred credibility. The characteristics of the study participants and participants' quotations were described in order to meet the criterion for transferability. The authors, who are experienced qualitative researchers, held discussions about both the interviews and data analysis to maintain consistency during the research process. This reinforced dependability. The discussions were recorded in notes and the results of discussions supported the categories decided on. An audit trail of the study process supported confirmability [18].

\section{Ethical Considerations}

This study was approved by the Internal Review Board of the first author's home institution. First, a letter was sent to the directors of nursing at 10 hospitals. The letter explained the purpose of this study, and provided information on the methods of data generation and the confidentiality agreements. The directors submitted the name of prospective participants for this study. Second, a letter that was almost the same as the one for the directors of nursing was sent to the prospective participants. Prospective participants became study participants when they 
agreed to participate in this study by sending an acceptance letter. All participants provided signed informed consent. The consent form included project descriptions, procedures, risks, benefits, and costs to the participant, as well as study withdrawal procedures and confidentiality agreements.

\section{RESULTS}

\section{Characteristics of Study Participants and their Clinical Units}

Table 1 shows the characteristics of the study participants and their clinical units where the study participants worked as nurse managers. The study participants' clinical experience as nurses ranged from 19 to 30 years with a median of 24 years. Their experience as a nurse manger ranged from 4 to 10 years with a median of 5 years. The hospitals employed from 6 to 120 NGNs. The number of NGNs assigned to the clinical units was between 1 and 8 with a mean of 3.3 .

All clinical units used a preceptor to teach NGNs. A preceptor is a nurse who has a role in guiding and supporting NGNs in practicing in their unit. The preceptor/NGN ratio varied. Two clinical units used a group teaching approach, which means there was more than one preceptor for each NGN. Eight clinical units had 1 or 2 advisors who supported preceptors with 3 to 6 years' experience. These advisors were a little older than the preceptors, usually having 5 to 10 years of nursing experience. The advisor's role was to help preceptors when the preceptors encountered difficulties in supporting NGNs.

\section{Strategies}

Six categories and 21 subcategories emerged from data analysis (Table 2). The six categories were: understanding the circumstances of NGNs, providing opportunities for experience and learning, supporting nurses who teach NGNs, facilitating self-learning, promoting awareness of being a nurse in the clinical unit, and strengthening the sense of comradeship in clinical units. The first three categories were standard practice when nurse managers work with NGNs in clinical units. Therefore, the description of the main results in this section mainly focus on the latter three strategies that are particularly important for the integration of NGNs into clinical units; namely, facilitating self-learning, promoting awareness of being a nurse in the clinical unit, and strengthening the sense of comradeship in clinical units. These strategies are explained briefly with illustrative quotations from the study participants.

\section{Facilitating Self-Learning}

The study participants were conscious of NGNs' learning situations and tried to facilitate their self-learning to aid them in taking good care of their patients. To facilitate selflearning, they expressed the necessity of autonomous thinking and learning by NGNs.

I told them, "You should feel confident about giving care to our patients. You must learn what you need to do... You will be taught once but after that you have to learn by yourself. If a patient asks you something, you should not ask other nurses without first thinking for yourself." (No. 6)

They recommended that NGNs learn at their own pace. Many study participants mentioned their concerns when there were more than 2 NGNs in their unit. If NGNs did not take care of an equal number of patients, the NGN who had

Table 1. Characteristics of Participants and their Units

\begin{tabular}{|c|c|c|c|c|c|c|}
\hline No. & Gender & $\begin{array}{c}\text { Clinical } \\
\text { Experiences as } \\
\text { a Nurse (Years) }\end{array}$ & $\begin{array}{l}\text { Experiences as a } \\
\text { Nurse Manager } \\
\quad \text { (Years) }\end{array}$ & Type of Unit & Education System & $\begin{array}{l}\text { NGNs Assign to the } \\
\text { Unit (Total NGNs Hired } \\
\text { by Hospital) }\end{array}$ \\
\hline 1 & Female & 20 & 8 & $\begin{array}{c}\text { Neurosurgery, Orthopedic } \\
\text { Surgery }\end{array}$ & $\begin{array}{c}\text { Three Preceptors for } 3 \text { NGNs } \\
\text { and one advisor }\end{array}$ & $3(18)$ \\
\hline 2 & Female & 24 & 5 & $\begin{array}{l}\text { Otorhinolaryngology, } \\
\text { Dental surgery, Plastic } \\
\text { surgery }\end{array}$ & $\begin{array}{c}\text { Teaching by } 4 \text { groups, which } \\
\text { including } 1 \text { preceptor for } 1 \\
\text { NGN and one advisor in one } \\
\text { group }\end{array}$ & $4(120)$ \\
\hline 3 & Female & 24 & 4 & $\begin{array}{c}\text { Mixed (Cardiovascular } \\
\text { medicine, Cardiac surgery, } \\
\text { Respiratory } \\
\text { medicine/surgery, etc.) }\end{array}$ & $\begin{array}{c}\text { One preceptor for } 1 \mathrm{NGN} \text { and } \\
\text { one advisor }\end{array}$ & $2(95)$ \\
\hline 4 & Female & 19 & 6 & Surgical center & $\begin{array}{c}\text { One preceptor for } 1 \mathrm{NGN} \text { and } 3 \\
\text { advisors }\end{array}$ & $5(16)$ \\
\hline 5 & Female & 26 & 10 & $\begin{array}{l}\text { Unit for people with } \\
\text { disabilities }\end{array}$ & $\begin{array}{c}\text { Two preceptors for } 1 \mathrm{NGN} \text { and } \\
\text { one advisor }\end{array}$ & $1(8)$ \\
\hline 6 & Female & 22 & 5 & ICU & One preceptor for $1 \mathrm{NGN}$ & $4(40)$ \\
\hline 7 & Female & 30 & 5 & Operating room & $\begin{array}{c}\text { One preceptor for } 1 \mathrm{NGN} \text { and } 2 \\
\text { advisors }\end{array}$ & $1(6)$ \\
\hline 8 & Female & 23 & 5 & Emergency department & $\begin{array}{c}\text { One preceptor for } 1 \mathrm{NGN} \text { and } 1 \\
\text { advisor }\end{array}$ & $8(49)$ \\
\hline 9 & Female & 29 & 10 & $\begin{array}{l}\text { Obstetrics \& Gynecology, } \\
\text { Immunology/hematology }\end{array}$ & $\begin{array}{c}\text { One preceptor for } 1 \mathrm{NGN} \text { and } 1 \\
\text { advisor }\end{array}$ & $2(56)$ \\
\hline
\end{tabular}


Table 2. Strategies to Facilitate Integration into Clinical Units

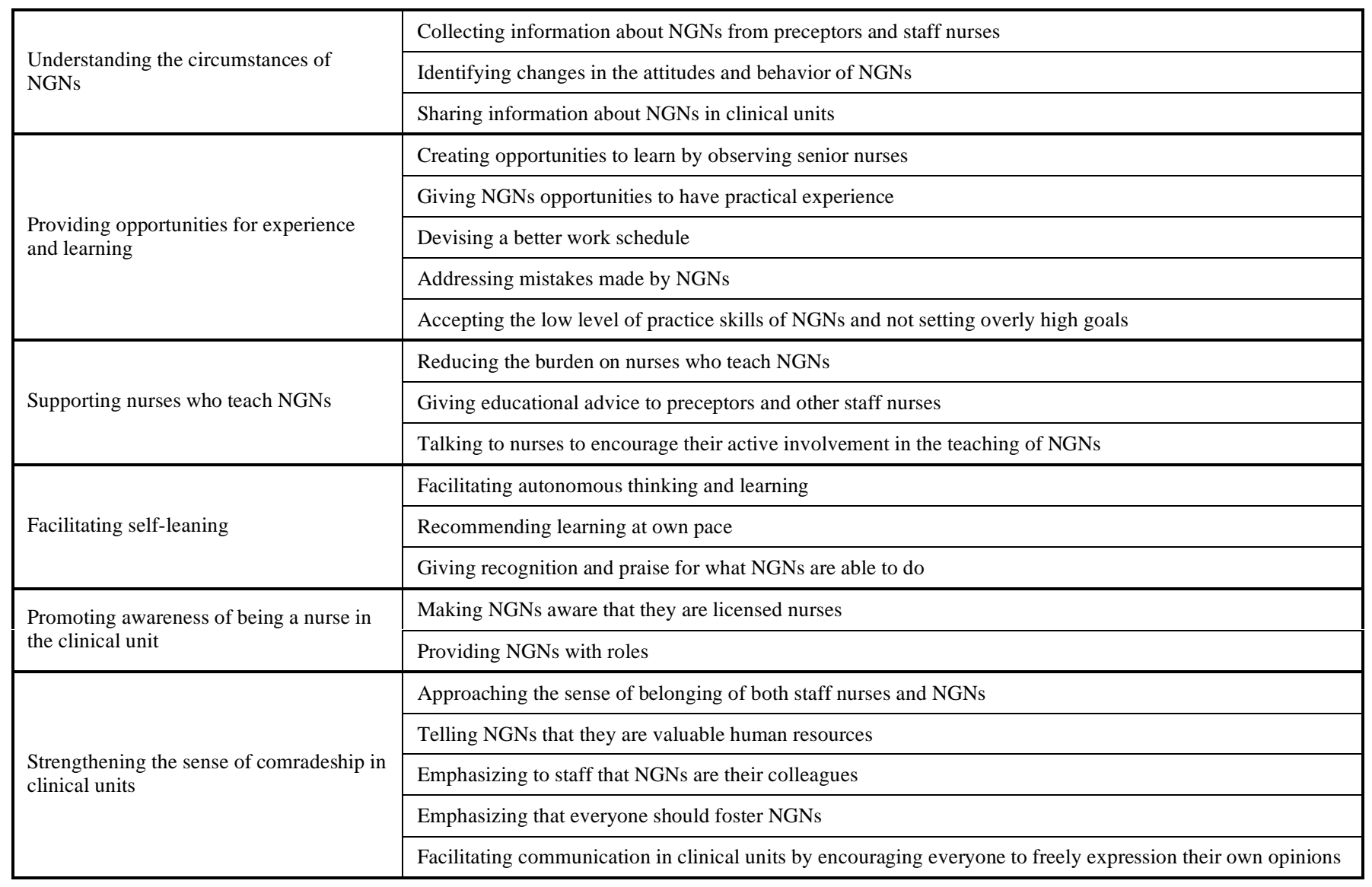

fewer patients thought that she/he was not good enough to work as a nurse. The study participants surmised that if NGNs were less inclined to compare their level of competence with that of others, this would reduce stress and help them focus more on learning.

"NGNs should know that everybody develops at a different pace. It is unrealistic to expect that the acquisition of knowledge and skills will take place at the same rate among all NGNs over a one- or two-year period... They should learn at their own pace." (No.1)

They also gave the NGNs recognition and praise for what they were able to do as a way to motivate their self-learning.

"Many NGNs are admonished by senior nurses or patients during this period (in the first 8 months after they start working). So, I try to find something positive about a NGN's work that I can tell them about. Anything is alright, for example, when talking about their patient, I may tell them that they observed the patient well ... The praise gives them motivation to learn more." (No.8)

"When I asked a nurse at the end of her first year a question, 'what made you change your mind when you wanted to quit working?', she answered that it was a senior nurse who praised her about her suctioning technique ... I think if NGNs feel that everybody is watching over them and giving them praise, it encourages NGNs to continue learning by themselves and working in this unit." (No. 1)

This strategy is related to the strategy of providing opportunities for experience and learning. The study participants created opportunities for NGNs to learn about nursing practice by observing senior nurses and using checklists of nursing skills. These learning opportunities could facilitate the self-learning of NGNs.

\section{Promoting Awareness of Being a Nurse in the Clinical Unit}

The study participants attempted to make NGNs more aware of the valuable role they play in their unit as a licensed nurse. They thought that by raising the awareness of NGNs of being licensed and professional nurses, this would aid their integration into their clinical unit.

"When NGNs received their pay slip, I handed it to them personally and told them that their work was recognized with a monetary reward. I don't know if they received my message but I wanted to tell them that ... I asked them to persist for another month. I continue to do this." (No. 3)

Another participant said that she gave a message card to NGNs when they received their first salary payment. The message was "This is the first payment you have received 
since acquiring your nursing license. Working as a nurse places a very heavy burden on you and you have real responsibilities as a nurse. Together, let's try hard to make sure you are able to fulfill your responsibilities." (No. 2)

The study participants also gave NGNs a real role to raise their awareness of being a nurse in their clinical unit.

"I told NGNs that if they were not working here, we would not be able to give our patients adequate care. It is true that we don't have extra human resource ... It is important to give NGNs a real role in the clinical unit. It doesn't need to be a big role. The first-year nurses usually said that they could not do anything even though they were working in the unit. I told them that they had a significant role to play even as first-year nurses." (No. 6)

"When NGNs have to provide care for a patient from admission to discharge, not just providing daily care on a routine basis, they feel a greater sense of responsibility to take care of their patient properly. ... Feeling responsible is important for the integration of NGNs into the unit." (No. 3)

The study participants believed that when NGNs were able to fulfill their respective roles, they felt that they were truly serving as a nurse in the unit. This feeling encourages NGNs to integrate into their clinical units.

\section{Strengthening the Sense of Comradeship in Clinical Units}

The study participants tried to strengthen the sense of comradeship in their clinical units by having regular contact with both NGNs and other staff nurses. With NGNs, they tried to enhance the NGNs' sense of belonging by thinking of them as a family member and telling them that NGNs are important members of the unit.

"To facilitate the sense of belonging, a low level approach was adopted. For example, if it was someone's birthday, I wished them 'happy birthday' in front of everyone in the morning before the day shift began. I believe that our team in this unit is like a family in society, so we should not forget the birthdays of our family members ... I also told NGNs that you are a member of this unit and other people think of you in that way ... You should try hard as a member of this unit." (No. 2)

"I told NGNs that each of them is an important human resource ... I asked for their opinions when we had a conference or a case study meeting at our unit. Even if they have an opinion it is hard for them to speak up. So I asked them, "what do you think?", (No. 4)

The study participants approached not only NGNs but also other staff members to strengthen the sense of comradeship in their clinical units through conducting common activities and solving problems. One participant who is a supervisor of a neurosurgery unit stated:

\begin{abstract}
"Our patients stay in our unit for a long time. When they move out of the acute stage and are discharged from hospital, we give patients a colorful piece of origami (traditional Japanese paper object made by folding paper). All members of our unit do something ... It started when a patient on a ventilator with no chance of recovery had a birthday ... We held a birthday party with her family in the patient's room. The present was a colorful piece of origami. Her family was very grateful for what we did ... This gives our nurses a strong sense of comradeship." (No. 1)

"If we have any problems about a new nurse education program, all of us discuss them ...We try to regard NGNs as integral members of this unit and adjust how we teach them to meet their needs and to solve problems together in our unit." (No. 9)
\end{abstract}

The study participants also emphasized that everyone should foster NGNs. They tried to convey the message that not only preceptors but also all nurses in a clinical unit should be concerned with NGN education.

"...NGNs are nurses all of us have the responsibility to foster. Each NGN has his or her own preceptor; however, I pair them for a night shift once in a term because it is not only the preceptor's responsibility to teach NGNs. Everybody who works on a night shift with a NGN should take care of the NGN...I create such an environment (where everybody in the unit fosters NGNs)..." (No. 4)

"At all times, we tried to express a feeling of welcome to NGNs ... NGNs are very nervous when they first come to our unit. We don't do anything special but we talk to them so they can become acquainted with the nurses in the unit ... Everybody thinks about how to welcome NGNs when March or April arrives. So they start making an education plan for NGNs together... I told them that it is very important what everybody did for NGNs." (No. 7)

\section{DISCUSSION}

In Japan, the voluntary turnover rate for first-year nurses in 2011 was $7.5 \%$, which was lower than the previous year [19]. Clinical training for NGNs was encouraged under new legislation from April 2010; therefore, many hospitals started or improved their training programs. While this could have been a factor contributing to the lower turnover rate, the endeavors of nurse managers to integrate NGNs into clinical units may have also have had an influence.

In order to facilitate NGNs' integration into the clinical unit, the nurse managers used a total of 6 strategies. The three strategies that were standard practice if NGNs were working in clinical units comprise understanding the circumstances of NGNs, providing opportunities for experience and learning, and providing support to nurses who teach NGNs. Regarding understanding the 
circumstances of NGNs, the nurse managers collected information about how NGNs were working from preceptors and staff nurses in order to gain a clear understanding of their situation. This strategy is vital to providing appropriate and timely support for NGNs in clinical units, and has a strong influence on NGNs' transition into practice and integration into the workplace [20]. It is imperative to provide NGNs with opportunities for experience and learning by working together in clinical units. While teaching NGNs, the nurse managers supported nurses who teach NGNs by giving them advice and motivating them in their teaching role. These 3 strategies make a meaningful contribution to NGNs' integration into clinical units; however, it is difficult to effectively facilitate such integration by these strategies alone.

The other 3 strategies that were particularly important were: facilitating self-learning, promoting awareness of being a nurse in the clinical unit, and strengthening the sense of comradeship in clinical units. To facilitate integration, it is essential for NGNs to acquire the knowledge and skills specific to the unit; therefore, nurse managers tried to facilitate self-learning of NGNs by providing opportunities for experience and learning. Salt et al. [21] reviewed articles to find organizational strategies that increase the retention rates of NGNs. One of the strategies identified was a program designed to develop specific clinical skills through such means as classroom instruction, observational experiences, case studies, and computer-based training.

The nurse managers could use methods, such as study sessions to address the specific skills needed in a particular unit, and debriefing sessions after stressful events such as emergency resuscitations [22] would be useful to expand NGNs' experience and learning opportunities. These opportunities should facilitate NGNs' self-learning. How willing NGNs are to exercise their clinical skills is affected by how they see themselves as members of the clinical unit [23]; therefore, to give NGNs the confidence to put their clinical skills into practice it is imperative for them to be integrated into their respective units.

In this study, 8 clinical units out of 9 had advisors for preceptors. The preceptor's role is to support socialization and facilitate the transition of NGNs into practice [24]. By contrast, the advisor's role is close to that of a mentor's in the U.S. They serve as a role model, teacher, coach, guide, and compensator for poor preceptor relationships [25]. The advisors were used as part of the preceptorship team to reduce the burden on preceptors and provide the NGNs with the most appropriate support in the clinical unit in the manner suggested by Beecroft et al. [26]. The preceptors' advisor was a nurse who had more experience than the preceptors; however, they usually did not have any special training on being an advisor. As the position of unit-based staff development specialist in charge of education in a clinical unit does not exist in Japan, nurse managers have to undertake the role of staff development specialist such as coach, facilitator, mentor, and consultant [11]. However, the nurse managers have limited time to fully master the specialist role of staff development. Training for preceptors and advisors is necessary to facilitate NGNs' integration into a clinical unit.
Clare and van Loon [27] identified best practice principles for the transition from a student to a registered nurse. Both NGNs and their employers recognized that the key issue for NGNs' positive transition was to genuinely welcome the NGNs and make them feel a part of the nursing team. The nurse managers themselves and other nurses expressed their feeling of welcome to NGNs and acknowledged NGNs' achievements in patient care. These actions are meaningful in terms of a NGN's sense that he or she has been accepted as a member of the unit.

NGNs' sense of belonging to their unit and feeling a part of unit culture were important for their integration into a clinical unit [3]. The study participants gave the NGNs roles to promote their awareness of being a nurse in their unit. This strategy could help to create sense of belonging, which helps the integration of NGNs. Recognition of the contribution that NGNs make to their clinical unit is essential for them to gain a feeling of being important [23]. Levett-Jones and Lathlean [28] indicated that belongingness relates to an individual's feeling of being secure, accepted, included, valued, and respected by a defined group. As one participant explained, all members of her unit celebrated a patient's discharge by giving them a colorful piece of origami. This practice helps to create the feeling of "being part of a collegial community" [23]. Wishing NGNs "happy birthday" is another way to promote this feeling. Fostering the sense of belonging is one way to promote comradeship, which in turn creates the sense of a collective purpose and the mentality that we are "in-it together" [29].

As a result of a literature review, Murphy and Sharp [30] found that perceptions of comradeship and peer communication were related to unit cohesion. The nurse managers' efforts to strengthen the sense of comradeship could make their units more cohesive. This environment should help NGNs to integrate into their clinical units. The Japanese in particular place a high value on the relatedness of individuals and the maintenance of harmony within the group [31]. Therefore, the strategy of strengthening the sense of comradeship in clinical units is central to facilitating the integration of NGNs in the Japanese cultural context.

This strategy, the strengthening of the sense of comradeship, also contributes to the creation of a supportive environment for NGNs, which is a significant component of NGNs' experience [32]. Miller [33] identified the dimensions of a supportive environment as consisting of team work, cohesiveness and shared values. Directors of nursing recommended the nurse managers for this study because they assumed that the nurses in their units were working together cohesively. These clinical units provide a supportive environment because of the nurse managers' endeavors to strengthen the sense of comradeship for both NGNs and other nurses.

Although there is a positive correlation between the initial orientation and job satisfaction and retention, the operational definition of orientation varies [10]. In Japan, unit orientation, which is usually the period during which NGNs are not assigned to a patient, is generally short, only one to three days. Even after NGNs are assigned to patients, there should be some form of ongoing orientation. A clearer definition of unit orientation and a plan for ongoing training that contains objectives are needed in each clinical unit. As 
one of study participants mentioned, all nurses who are working at the unit should be involved in making an orientation program for the unit. If everyone provides input for the program, they will be more interested in the education of NGNs in the unit. This should create welcoming atmosphere for NGNs.

Furthermore, as Duchscher [34] indicated, it is important to include information about NGNs' role transition in the orientation program. NGNs did not have a high skill level or confidence; therefore, an extended orientation and support program in each clinical unit are essential to facilitate transition into practice. Information on how NGNs experience role transition is important not only for NGNs but also for all nurses in the unit so that adequate support can be given to NGNs.

This study has several limitations. The study participants were confined to nurse managers whose units were evaluated by the directors of nursing as units where the nurses were working together cohesively. Therefore, the possibility exists that the findings of this study were influenced by this sampling method. The authors concluded that data analysis had reached saturation because no new categories emerged; however, if more interviews had been conducted, specific practices may have been discovered rather than new categories. Regarding a NGN's integration into a clinical unit, their preceptors and other staff nurses also have important roles to play. Research that incorporates these nurses is needed. Furthermore, this study examined strategies adopted by nurse managers; therefore, the study has not been able to verify if these strategies work for NGNs. Useful strategies from a NGN viewpoint should be identified in the future.

\section{CONCLUSIONS}

The nurse managers adopted 6 strategies and 3 of them were particularly important for facilitating the integration of NGNs into clinical units: facilitating self-learning, promoting awareness of being a nurse in the clinical unit, and strengthening the sense of comradeship in clinical units. The nurse managers tried to facilitate NGNs' self-learning by providing opportunities for experience and learning. NGNs' acquisition of knowledge and skills specific to their clinical unit are imperative for NGNs to be a member of the unit. They also tried to raise the NGN's awareness of being a nurse in the clinical unit by giving them meaningful roles within the unit.

The central strategy was the strengthening the sense of comradeship of all nurses in their clinical units. This strategy should create a supportive environment for NGNs to integrate into their respective clinical units. The nurse managers implemented this strategy by creating the sense of belonging among both staff nurses and NGNs. To facilitate NGNs' integration into their clinical units, nurse managers need to adopt strategies that are not confined to NGNs but include all nurses in their clinical units.

All senior nurses who worked with NGNs could apply these strategies to facilitate NGNs' integration into their clinical units. For NGNs, knowing these strategies would help them to understand what they should do to become a full member of their unit.

\section{CONFLICT OF INTEREST}

The authors confirm that they have no conflict of interest in regard to this manuscript.

\section{ACKNOWLEDGEMENTS}

We would like to express our grateful appreciation to the nurse managers who participated in this study for sharing their practices and insights.

This study was supported by a KAKENHI (22592401) Grant-in-Aid for Scientific Research (C) of the Japan Society for the Promotion of Science (JSPS) .

\section{ETHICAL APPROVAL}

This study was approved by the ethical committee of Kobe City College of Nursing, Kobe, Japan. The ethical approval number: 2010-1-10.

\section{REFERENCES}

[1] Kramer M. Reality shock: why nurses leave nursing. CV Mosby Company, St Louis 1974.

[2] Gregg M F, Shigematsu T, Hayashi C, Kono M, Yoshida K. Newly licensed nurses' experiences in rotational training programs in Japan. J Contin Educ Nurs 2011; 42 (2): 89-96.

[3] Fink R, Krugman M, Casey K, Goode C. The graduate nurse experience: qualitative residency program outcomes. J Nurs Adm 2008; 38(7/8): 341-8.

[4] McKenna L G \& Green C. Experiences and learning during a graduate nurse program: an examination using a focus group approach. Nurse Educ Pract 2004; 4(4), 258-63.

[5] AONE guiding principles for the newly licensed nurse's transition into practice; [cited 2013 January 15] Available from: http://www.aone.org/resources/PDFs/AONE_GP_Newly_Licensed _Nurses.pdf

[6] Van Maanen J, Shein EH. Toward a theory of organizational socialization. Res Organ Behav 1979; 1: 209-64.

[7] Japanese Nursing Association (2004). Early turnover situations of newly graduated nurses 2004; [cited 2013 January 10] Available from: http://www.mhlw.go.jp/shingi/2006/03/dl/s0329-13b-5-3.pdf. (In Japanese)

[8] Whitehead J. Newly qualified staff nurses' perceptions of the role transition. Br J Nurs 2001; 10(5): 330-9.

[9] Halfer D, Graf E. Graduate nurse perceptions of the work experience. Nur Econ 2006; 24(3): 150-5.

[10] Scott ES, Engelke MK, Swanson M. New graduate nurse transitioning: Necessary or nice? Appl Nurs Res 2008; 21: 75-83.

[11] Santucci J. Facilitating the transition into nursing practice: concepts and strategies for mentoring new graduates. J Nurs Staff Dev 2004; 20(6): 274-84.

[12] Orsini $\mathrm{CH}$. A nurse transition program for orthopaedics: creating a new culture for nurturing graduate nurses. Orthop Nurs 2005; 24(4): 240-8.

[13] Persaud D. Mentoring the new graduate perioperative nurse: a valuable retention strategy. AORN J. 2008; 87(6): 1173-9.

[14] Sandelowski M. Whatever happened to qualitative description? Res Nurs Health 2000; 23(4): 334-40.

[15] Miles MB, Huberman AM. Qualitative Data Analysis: An expanded sourcebook. Thousand Oaks, CA: Sage Publications, 1994.

[16] Gregg MF, Asahara K, Yokoyama M. How to Conduct and Report Qualitative Research: Aiming to be an Expert of Nursing Research. Tokyo: Ishiyaku Publishers, 2011. (In Japanese)

[17] Lincoln YS, Guba EG. Naturalistic inquiry. Newbury Park, CA: Sage 1985.

[18] Shenton AK. Strategies for ensuring trustworthiness in qualitative research projects. Educ Infom 2004; 22: 63-75.

[19] Japanese Nursing Association. News release: results of the investigation of actual conditions of nurses in hospitals 2013. [cited 2013 March 29] Available from: http: //www.nurse.or.jp/up_pdf/ 20120806122153_f.pdf (In Japanese)

[20] Walker A, Earl C, Costa B, Cuddihy L. Graduate nurses' transition and integration into the workplace: A qualitative comparison of 
graduate nurses' and Nurse Unit Managers' perspectives. Nurs Educ Today 2013; 33(3): 291-6.

[21] Salt J, Cummings GG, Profetto-McGrath J. Increasing retention of new graduate nurses: a systematic review of interventions by healthcare organizations. J Nur Admin. 2008; 38(6): 287-96.

[22] Halfer D. A magnetic strategy for new graduate nurses. Nurs Econ 2007; 25(1): 6-11.

[23] Thrysoe L, Hounsgaard L, Dohn NB, Wagner L. Newly qualified nurses-experiences of interaction with members of a community of practice. Nurs Educ Today 2012; 32(5): 551-5.

[24] Moore P, Cagle CS. The lived experience of new nurses: importance of the clinical preceptor. J Contin Educ Nurs 2012; 43(12): 555-65.

[25] Beecroft PC, Santner S, Lacy ML, Kunzman L, Dorey F. New graduate nurses' perceptions of mentoring: six-year programme evaluation. J Adv Nurs 2006; 55(6): 736-47.

[26] Beecroft P, Hernandez AM, Reid D. Team preceptorship: A new approach for precepting new nurses. J Nurs Staff Dev 2008; 24(4): 143-8.

[27] Clare J, van Loon A. Best practice principles for the transition from student to registered nurse. Collegian 2003; 10(4): 25-31.
[28] Levett-Jones T, Lathlean J. Belongingness: A prerequisite for nursing students' clinical learning. Nurse Educ Pract 2008; 8(2): 103-11.

[29] Riordan C. Comradeship at work. [cited 2013 September 14] Available from: http: //beforeitsnews.com/international/2013/07/co mradeship-at-work-2461894.html

[30] Murphy D, Sharp D. Exploring Pre-enlistment and Military Factors Associated With the Morale of Members of the UK Armed Forces. Mil Med 2011; 176(1): 13-8.

[31] Markus HR, Kitayama S. Culture and the self: Implications for cognition, emotion, and motivation. Psychol Rev 1991; 98(2): 22453 .

[32] Goh K, Watt E. From 'dependent on' to 'depended on': the experience of transition from student to registered nurse in a private hospital graduate program. Aust J Adv Nurs 2003; 21(1): 14-20.

[33] Miller JF. Opportunities and obstacles for good work in nursing. Nurs Ethics 2006; 13(5): 471-87.

[34] Duchscher JE. Transition shock: the initial stage of role adaptation for newly graduated Registered Nurses. J Adv Nur 2009; 65 (5): 1103-13.

(C) Gregg et al.; Licensee Bentham Open.

This is an open access article licensed under the terms of the Creative Commons Attribution Non-Commercial License (http://creativecommons.org/licenses/by-nc/3.0/) which permits unrestricted, non-commercial use, distribution and reproduction in any medium, provided the work is properly cited. 